\title{
Mechanism of Microwave Activation on Molybdenite
}

\author{
Shuangping Yang, Tiantian Zhang *, Shouman Liu and Haixing Sun
}

\section{check for}

updates

Citation: Yang, S.; Zhang, T.; Liu, S.; Sun, H. Mechanism of Microwave Activation on Molybdenite. Materials 2021, 14, 5486. https://doi.org/ $10.3390 / \mathrm{ma} 14195486$

Academic Editor: Dinesh Agrawal

Received: 23 July 2021

Accepted: 18 September 2021

Published: 22 September 2021

Publisher's Note: MDPI stays neutral with regard to jurisdictional claims in published maps and institutional affiliations.

Copyright: (c) 2021 by the authors. Licensee MDPI, Basel, Switzerland. This article is an open access article distributed under the terms and conditions of the Creative Commons Attribution (CC BY) license (https:// creativecommons.org/licenses/by/ $4.0 /)$.
School of Metallurgical Engineering, Xi'an University of Architecture and Technology, Xi'an 710055, China; yang_sping@163.com (S.Y.); Liusm617100@163.com (S.L.); 18434162589@163.com (H.S.)

* Correspondence: ztt15129236642@163.com; Tel.: +86-151-2923-6642

\begin{abstract}
The effect of microwave activation on the properties of oxidation roasting for molybdenite was investigated under the protection of inert gas, and the specific surface area, the oxidation properties, lattice constant, microstructure, and shape of molybdenite were analyzed and characterized by a laser particle size analyzer, thermogravimetry (TG), X-ray diffractometry (XRD) and scanning electron microscopy (SEM). The results show that microwave activation could effectively reduce the residual amount of sulfur in the molybdenum calcine and decrease the average particle size of molybdenite while increasing the specific surface area of molybdenite. On increasing the microwave activation power, the crystal cell volume and grain size of $\mathrm{MoS}_{2}$ reduced, and the microstrain increased slightly. At the same time, the surface shape of molybdenite became looser, but the layered structure is not changed. In addition, the oxidation property changed significantly; microwave activation promoted the oxidation reaction of molybdenite above $538^{\circ} \mathrm{C}$, and the rate of weight loss increased from $6.177 \%$ to $7.718 \%$ at $620{ }^{\circ} \mathrm{C}$.
\end{abstract}

Keywords: mechanism; microwave activation; molybdenite; specific surface area; microstrain

\section{Introduction}

Molybdenum, low alloy-based material of molybdenum and molybdenum compounds, is widely used in metallurgical, chemical, and nuclear applications, for building materials, metal pressure machining, machinery, military, and other industries [1-3]. Molybdenum is a refractory rare metal with high strength and corrosion resistance. At present, there are only four mineral sources for molybdenum with application value, i.e., molybdenite $\left(\mathrm{MoS}_{2}\right), \mathrm{CaMoO}_{4}, \mathrm{Fe}\left[\mathrm{MoO}_{4}\right]_{3} \cdot 7 \mathrm{H}_{2} \mathrm{O}$, and $\mathrm{PbMoO}_{4}$. Most molybdenum in the world exists in the form of molybdenite $\left(\mathrm{MoS}_{2}\right)$, it is the main raw material for extracting molybdenum. Molybdenite is typically used as a catalyst, lubricant, and raw material for the production of electronic components. It is soft, has a metallic luster, and like graphite, it is a thin plate or squamous crystal. In industry, oxidative decomposition along with the ammonia leaching process is generally used for treating molybdenite. The oxidative decomposition process mainly includes oxidizing, roasting, decomposition, and hydrodecomposition. Oxidizing-roasting-decomposition is the main technological process for disposing of molybdenite due to its advantage of low consumption and low cost [4-8], while hydro-decomposition requires expensive equipment [9]. Byung-Su Kim et al. [10] studied the effects of temperature and particle size on oxidative roasting of low-grade molybdenite concentrate. A, M, Abdel-Rehim [11] studied the thermal analysis of oxidative roasting of Egyptian molybdenite. Ebrahimi Kahrizsangi et al. [12] studied thermal analysis of Molybdenite oxidation and demonstrated its oxidation begins at $350{ }^{\circ} \mathrm{C}$. Gan et al. [13] studied the reactivity of low-grade molybdenum concentrates during oxidative roasting. Chen et al. [14] studied and identified the optimum conditions for the extraction of molybdenum from low-grade molybdenum concentrates by calcium-based roasting and acid leaching processes. In addition, the more chemically stable is the sulfide, the more difficult is the extraction. Thus, either drastic reaction conditions are required or the chemical stability of sulfides has to be modified by a suitable pre-leaching treatment. Hu et al. [15] studied 
structural changes in mechanically activated molybdenite and the effect of mechanical activation on molybdenite. The result shows that mechanically activated molybdenite is easier to be oxidized than unactivated molybdenite. However, the process of mechanical activation is complex and it consumes significantly high energy. Therefore, it is necessary to develop a low energy consuming and high-efficiency method to activate molybdenite.

Microwave heating, as a special heating method, is on the basis of conductivity of the material, magnetic permeability, and dielectric constant, which can generate heat effectively throughout the material [16]. Microwave heating is widely used in many fields due to its high heating rates, reduced processing time, and significant energy saving [17]. The selective heating and non-thermal effect can effectively change the structure and properties of the minerals. Iron ore can be reduced by carbothermal reduction in microwave field to obtain metallic iron [18,19]. Mohsen Farahat et al. [20] showed that the magnetic properties of molybdenite remained unchanged after microwave treatment. Guo et al. [21] studied the characteristics of the microwave drying and dehydrating process for molybdenum, and claimed that the energy required was twice as much as that required for conventional drying.

In this article, the structure and properties of non-activated molybdenite, as well as microwave, activated molybdenite, were investigated for the first time to reveal the mechanism of microwave activation on molybdenite and the effect of microwave activation on the properties of oxidation roasting.

\section{Experiment Procedure}

\subsection{Materials}

Molybdenite was obtained from the Jinduicheng Molybdenum Co., Ltd. (Xi'an, China), and its chemical composition is shown in Table 1. Molybdenite (mineral) has $52.21 \mathrm{wt} . \%$ of molybdenum, and the main gangues are $\mathrm{SiO}_{2}, \mathrm{CaO}$, and $\mathrm{MgO}$. The particle size analysis and XRD patterns of molybdenite are shown in Table 2 and Figure 1, respectively. It can be seen from Figure 1 that molybdenum mainly exists in the form of $\mathrm{MoS}_{2}$.

Table 1. Chemical composition of molybdenite (\%).

\begin{tabular}{cccccccccccc}
\hline $\mathbf{M o}$ & $\mathbf{S}$ & $\mathbf{C u}$ & $\mathbf{P b}$ & $\mathbf{W O}_{3}$ & $\mathbf{B i}$ & $\mathbf{C}$ & $\mathbf{K}$ & $\mathbf{F e}$ & $\mathrm{SiO}_{2}$ & $\mathbf{C a O}$ & $\mathbf{M g O}$ \\
\hline 52.21 & 34.83 & 0.11 & 0.09 & 0.10 & 0.05 & 0.40 & 0.09 & 0.33 & 5.20 & 1.70 & 4.89 \\
\hline
\end{tabular}

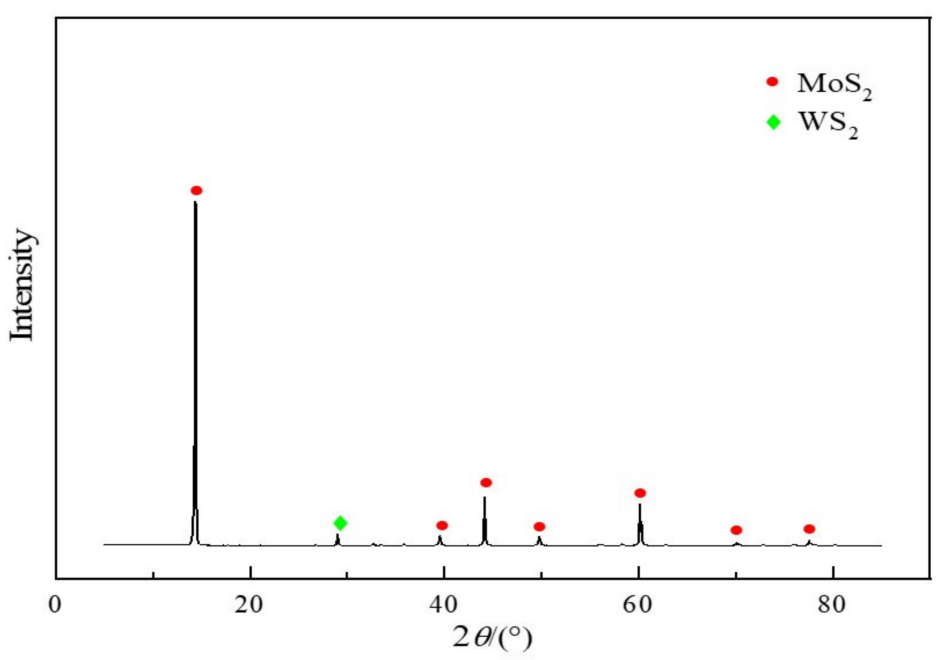

Figure 1. XRD pattern of the molybdenite. 
Table 2. Particle size distribution of molybdenite.

\begin{tabular}{ccc}
\hline & Mass Fraction/\% & \\
\hline$>0.044 \mathrm{~mm}$ & $0.036 \sim 0.044 \mathrm{~mm}$ & $<0.036 \mathrm{~mm}$ \\
0.14 & 8.66 & 91.2 \\
\hline
\end{tabular}

\subsection{Preparation of Microwave Activated Molybdenite}

The preparation of microwave-activated molybdenite was carried out by the microwave chemical synthesizer (MKX-R1C1C, Qingdao Maikewei Microwave Innovation Technology Co., Ltd., Qingdao, China). First, $30 \mathrm{~g}$ of molybdenite was loaded into a quartz tube $35 \mathrm{~mm}$ in diameter and $800 \mathrm{~mm}$ in length. $\mathrm{N}_{2}$ was passed through the quartz tube at a flow rate of $0.5 \mathrm{~L} / \mathrm{min}$ for $5 \mathrm{~min}$ before starting the microwave oven. Then, $\mathrm{N}_{2}$ was passed through the quartz tube at a rate of $1 \mathrm{~L} / \mathrm{min}$ after opening the microwave oven. The molybdenite was radiated with microwaves for 6 min at $450 \mathrm{~W}, 550 \mathrm{~W}$, and $650 \mathrm{~W}$ of power, respectively (a unique sample for each series of power, the repeatability of the process has been verified). Finally, $\mathrm{N}_{2}$ flow was stopped until the temperature dropped below $100{ }^{\circ} \mathrm{C}$, and the microwave-activated molybdenite was taken out and tested. The microwave-activated molybdenite samples were named P-450, P-550, and P-650, respectively.

\subsection{Oxidization Roasting Experiment and Determination of Sulfur Content}

The oxidization roasting of the microwave activated molybdenite and nonactivated molybdenite (P-0) were carried out in ceramic crucibles, heated in a high-temperature resistance furnace (SK-2-12, Tianjin Intermediate Belt Experiment Electric Stove Co., Ltd., Tianjin, China) under air current at a temperature of $600^{\circ} \mathrm{C}$ for $2 \mathrm{~h}$ and after the removal of sulfur dioxide gas, oxidized molybdenite was obtained. The calcined molybdenum was removed after roasting and tested. Being on the basis of the microwave power used in the previous steps, the molybdenum calcine samples were named M-0, M-450, M-550, and M-650, respectively.

\subsection{Analysis and Characterization}

The sulfur content in the molybdenum calcine samples was measured by a highfrequency infrared carbon and sulfur analyzer (JS-HW2000A, Nanjing Jinshi Analysis Instrument Factory, Nanjing, China).

Particle size was analyzed by a laser particle size analyzer (Ls-800, Zhuhai OMEC Instruments Co., Ltd., Zhuhai, China), with $95 \%$ ethanol as the dispersant, and the specific surface area (SG) of the samples was calculated from the particle size distribution.

The X-ray diffraction patterns of the microwave-activated molybdenite and nonactivated molybdenite were recorded by an X-ray diffractometer (Rigaku International Corporation, Tokyo, Japan) with $\mathrm{Cu} \mathrm{k} \alpha$ radiation at $40 \mathrm{kV}$ and $20 \mathrm{~mA}$. Then diffraction peaks (002) and (008) were chosen for the different molybdenites, the corresponding lattice constants, average grain size $(D)$, and microstrain $(\varepsilon)$ were calculated by the method of Hall, the Gaussian function model, and the Jade software (Livermore, CA, USA), respectively.

The microstructures of the samples were investigated by a scanning electron microscope (JSM-5600LV, JEOL, Tokyo, Japan).

The thermal analysis study of the samples was carried out with a comprehensive thermal analyzer (STA409PC, NETZSCH, Bavaria, Germany), with $5 \mathrm{mg}$ of sample; temperatures ranging from ambient to $700{ }^{\circ} \mathrm{C}$, in air, at a heating rate of $10^{\circ} \mathrm{C} / \mathrm{min}$.

\section{Results and Discussion}

\subsection{Sulfur Content of Molybdenum Calcine Samples}

The sulfur contents of the molybdenum calcine samples are shown in Figure 2. M450, M-550, and M-650 had sulfur content lower than that in M-0, and as microwave activation power increased, the sulfur content in the molybdenum calcine samples de- 
creased significantly. This can be attributed to molybdenite being oxidized more fully after microwave activation.

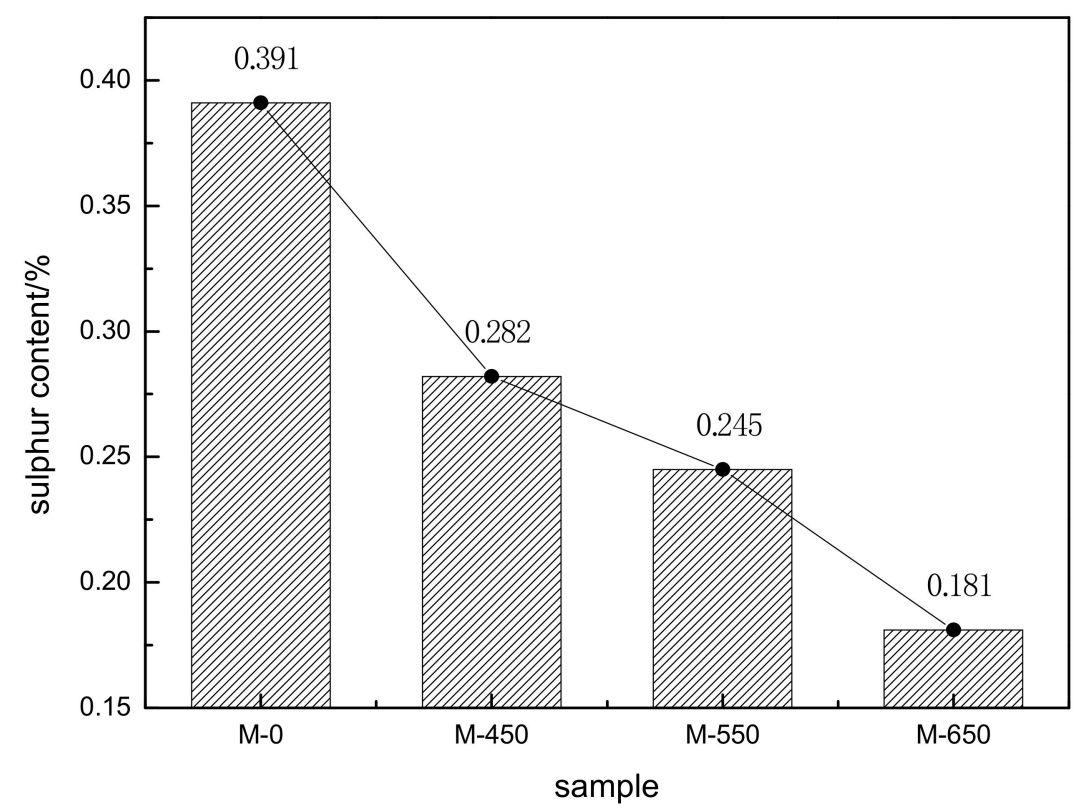

Figure 2. Sulfur content of the different samples.

\subsection{Specific Surface Area (SV)}

The relationship between specific surface area and power is shown in Figure 3.

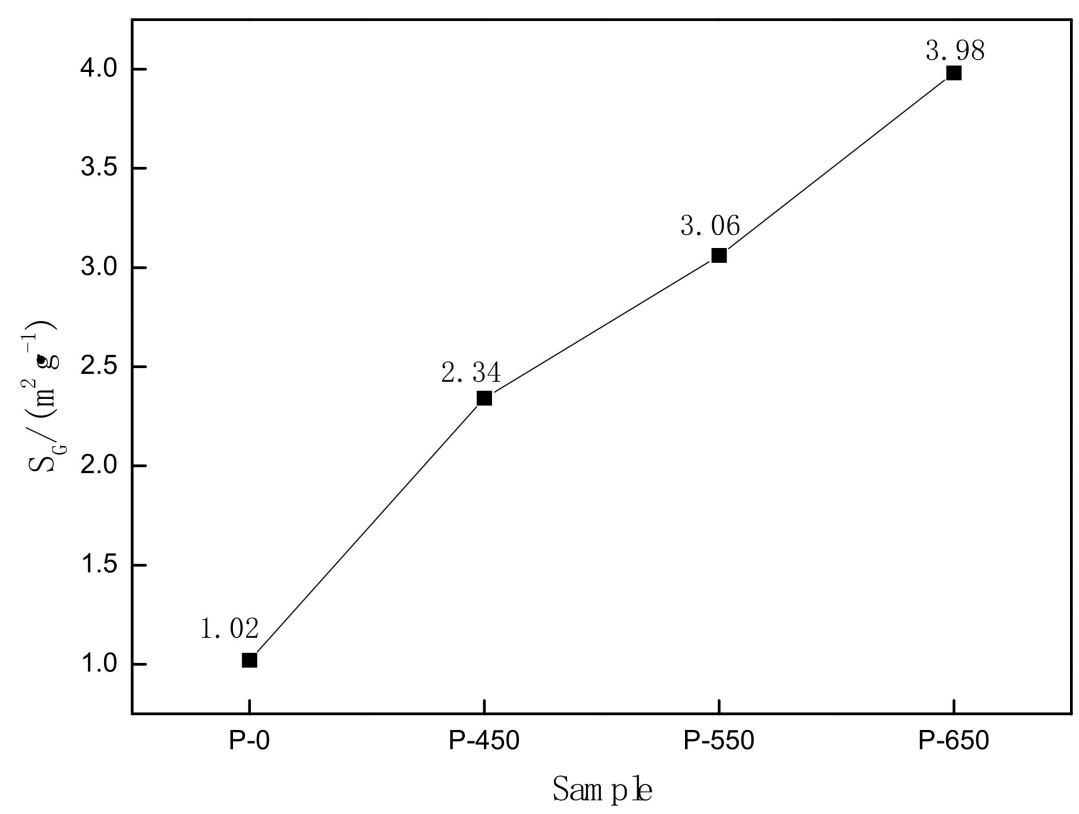

Figure 3. Relationship between specific surface area and power.

Figure 3 shows that microwave activation reduced the average particle diameter and increased the specific surface area of molybdenite, which can be explained by the following three reasons:

(1) In the microwave field, $\mathrm{MoS}_{2}$ and gangue have different heating rates and they can be heated up to different temperatures because of their different abilities to absorb microwaves. The obvious temperature difference between them can produce thermal stress, which can generate cracks when thermal stress reaches a certain level. The 
generation of cracks can effectively promote the monomer dissociation of $\mathrm{MoS}_{2}$, thereby increasing the specific surface area of the molybdenite [22].

(2) Due to the uneven distribution of the molybdenite components, the dispersed distribution of $\mathrm{MoS}_{2}$ can also lead to an obvious selective heating phenomenon, making internal cracks and increasing the specific surface area of the molybdenite [23].

(3) According to the isothermal gas equation, $P \cdot V=n \cdot R \cdot T$, the higher is the temperature, the greater is the pressure of the gas. Microwave heating occurs from the inside out, so the internal gas pressure is greater than that outside. The internal gas tends to spread outward and promote the generation of cracks. In addition, the higher the microwave power, the more obvious the change is. This can be attributed to the microwave field, the material absorbing energy can be expressed by Equation (1) [24], $\varepsilon_{0}$ is the permittivity of vacuum, $\varepsilon_{0}=8.85 \times 10^{-12} \mathrm{~F} / \mathrm{m}$; where $\varepsilon$ is the loss factor, $\mathrm{F} / \mathrm{m}$; $\operatorname{tg} \delta$ is the loss of dielectric tangent; $E$ is the electric field intensity of internal material, $\mathrm{V} / \mathrm{m}$; and $V$ is the volume of material, $\mathrm{m}^{3}$. It can be seen that if $f$ and $V$ remain unchanged, increasing the microwave power can strengthen the capacity of the material to absorb the microwave directly. The selective heating effect will be more obvious, and the specific surface area of molybdenite will gradually increase.

$$
W=2 \pi f \varepsilon_{0} \varepsilon^{\prime \prime} \operatorname{tg} \delta|E|^{2} V
$$

\subsection{Analysis of XRD and SEM}

X-ray diffraction peaks (002) and (008) for different molybdenite specimens are shown in Figure $4 a, b$. It is evident that with the increase of microwave radiation power, peaks (002) and (008) of molybdenite surrounded area gradually decreases, and the width of the half peak gradually increases. Therefore, the grain size of the molybdenite decreases after microwave activation according to the Scherrer formula.
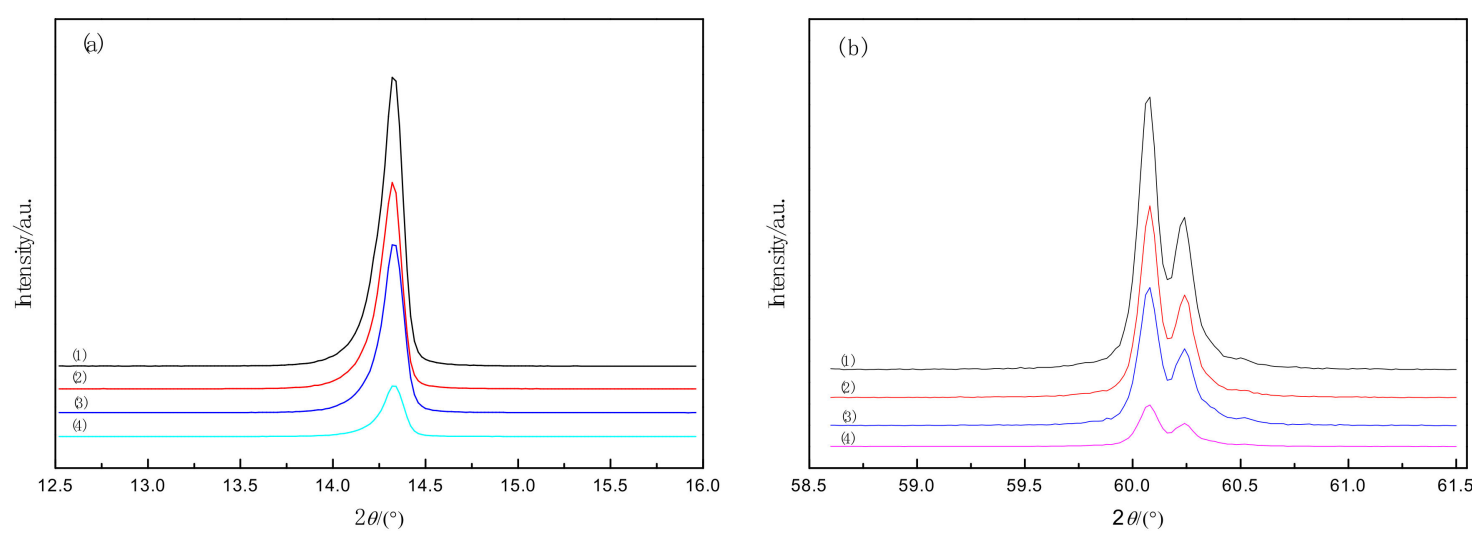

Figure 4. Peaks of XRD patterns for different molybdenite samples (a) (002) peak and (b) (008) peak. (1) P-0; (2) P-450; (3) P-550; (4) P-650.

The lattice constant, average grain size $(D)$, and microstrain $(\varepsilon)$ of unactivated molybdenite, as well as microwave, activated molybdenite are shown in Table 3. It can be seen that $\mathrm{MoS}_{2}$ is distorted after the treatment of microwave activation. With the increase of microwave power, the values of lattice constants $a, b$, and $c$, and $D$ decreased gradually, while the value of $\varepsilon$ increased slightly. The dissociation effect and activation effect of the microwave on the molybdenite is illustrated [25]. 
Table 3. Lattice constant, average grain size $(D)$, and microstrain $(\varepsilon)$ of nonactivated and microwave activated molybdenite.

\begin{tabular}{cccccccc}
\hline System & $\begin{array}{c}\boldsymbol{a}=\boldsymbol{b} / \\
\mathbf{n m}\end{array}$ & $\begin{array}{c}\boldsymbol{c l} \\
\mathbf{n m}\end{array}$ & $\begin{array}{c}\boldsymbol{\alpha}=\boldsymbol{\beta} / \\
\left({ }^{\circ}\right)\end{array}$ & $\begin{array}{c}\gamma / \\
\left.\mathbf{(}^{\circ}\right)\end{array}$ & $\begin{array}{c}\text { Lattice Volume/ } \\
\mathbf{n m}^{\mathbf{3}}\end{array}$ & $\begin{array}{c}\boldsymbol{D} / \\
\mathbf{n m}\end{array}$ & $\begin{array}{c}\boldsymbol{\varepsilon} / \\
\mathbf{\%}\end{array}$ \\
\hline P-0 & 0.31659 & 1.23142 & 90 & 120 & 0.10689 & 86.9 & 0 \\
P-450 & 0.31646 & 1.23156 & 90 & 120 & 0.10681 & 79.1 & 0.104 \\
P-550 & 0.31644 & 1.23055 & 90 & 120 & 0.10672 & 74.0 & 0.119 \\
P-650 & 0.31640 & 1.22947 & 90 & 120 & 0.10662 & 72.4 & 0.148 \\
\hline
\end{tabular}

The microwave activation had only a small effect on the structure of the molybdenite, which may be related to the special structure of molybdenite and its change in shape during microwave activation. The SEM analysis of molybdenite in Figure 5a-d shows that the surface shape of molybdenite becomes looser after microwave activation. This indicates that microwave activation can improve the thermodynamics and kinetics conditions of the oxidation roasting process of molybdenite, thereby decreasing the sulfur content of the product. However, microwave activation cannot change the inherent lamellar structure of the molybdenite. This can be attributed to the hexagonal plate of molybdenite; thus, it shows excellent cleavage. Layers are connected by very strong van der Waals force; when subjected to the external force, each layer can slide along the cleavage easily, which results in reduced lattice deformation and maintains the inherent lamellar structure [26].

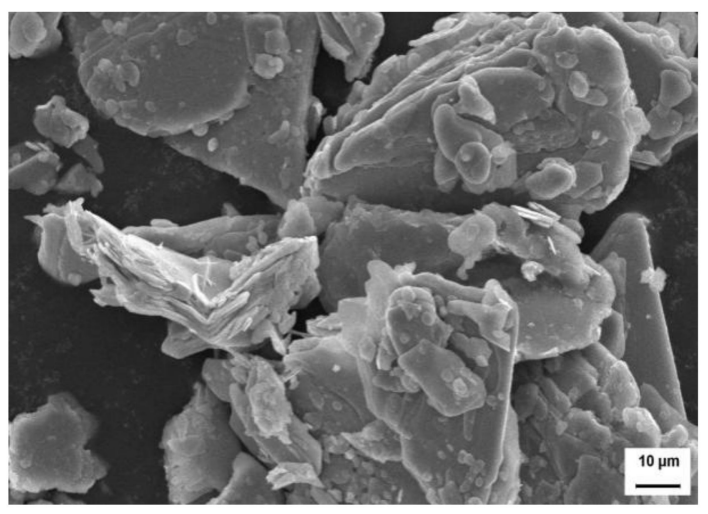

(a)

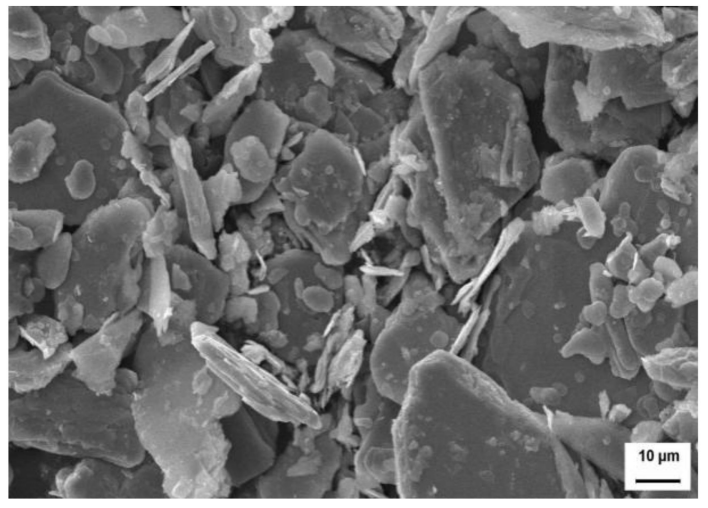

(c)

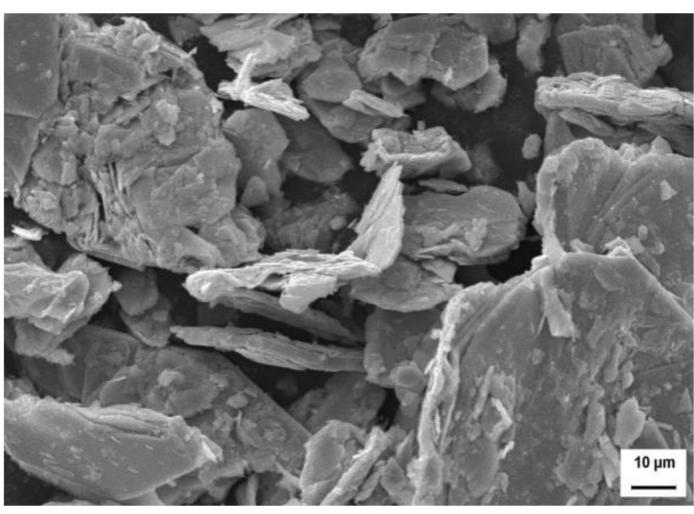

(b)

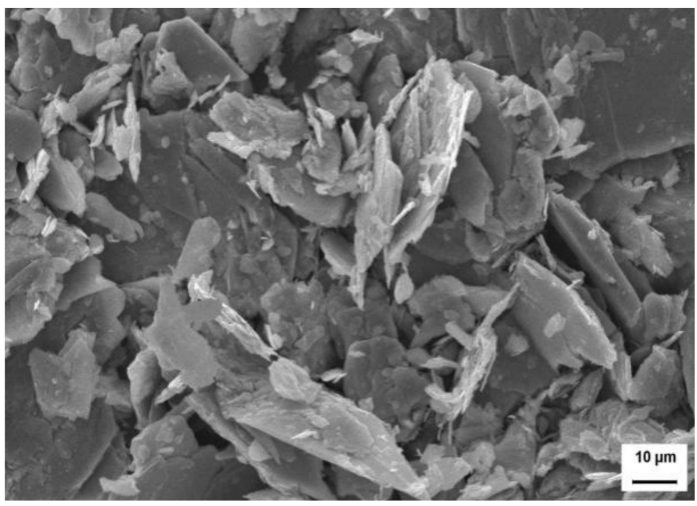

(d)

Figure 5. SEM images of molybdenite (a) $t=0 \mathrm{~min}$; (b) $t=3 \mathrm{~min}$; (c) $t=6 \mathrm{~min}$; (d) $t=9 \mathrm{~min}$.

\subsection{Analysis of the TG Curve}

The TG curves for nonactivated and microwave-activated molybdenite samples are presented in Figure 6. It shows that the weight loss of all molybdenite samples starts at $440{ }^{\circ} \mathrm{C}$. In addition, different samples have different mass loss ratios above $538{ }^{\circ} \mathrm{C}$. 
The result suggests that microwave activation only promotes the oxidation reaction of molybdenite above $538^{\circ} \mathrm{C}$. The mass loss ratio at $620^{\circ} \mathrm{C}$ for different molybdenite samples in the TG curves is also presented in Table 4, which can be explained by the following:

(1) The increase in the specific surface area and the value of $\varepsilon$ with the increased power of microwave add an effective reaction area between the molybdenite and oxygen.

(2) In the presence of the microwave, both polar and nonpolar molecules are polarized, which results in the exchange between microwave energy stored in the molecule and the average kinetic free energy of the molecule, reducing the activation energy and promoting the reaction process.

(3) The frequency of the microwave is very high, which may be close to the natural vibration frequency of the molecule; this may cause vibrations caused by microwave fracture of different chemical bonds, thereby promoting selective reaction activity [27-29].

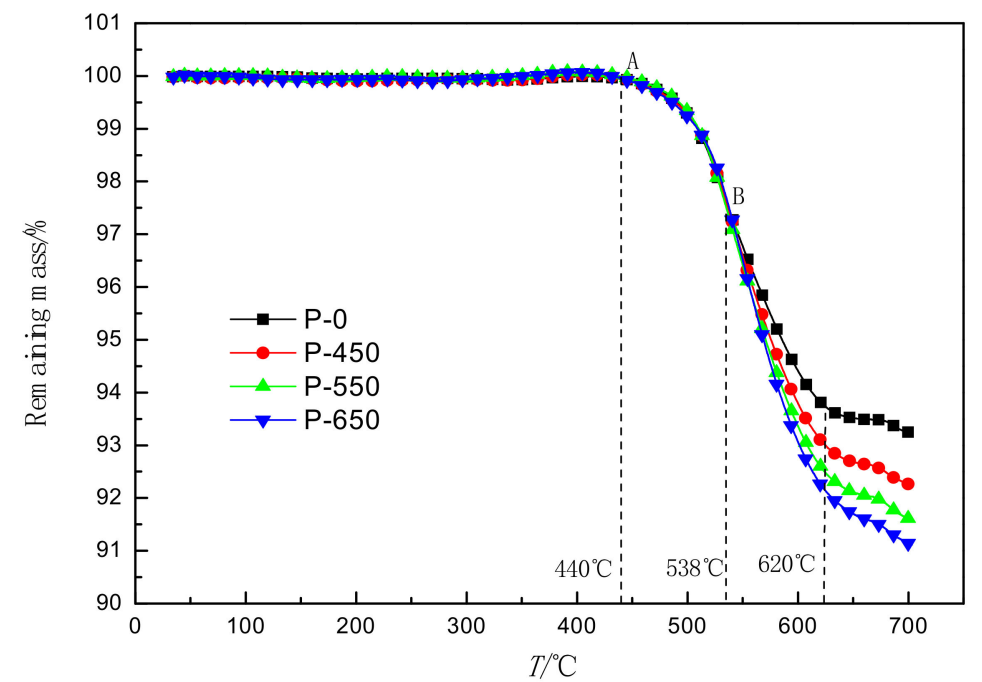

Figure 6. TG curves of the different samples.

Table 4. The mass loss ratio at $620^{\circ} \mathrm{C}$ for different molybdenites in the TG curves.

\begin{tabular}{ccccc}
\hline Samples & P-0 & P-450 & P-550 & P-650 \\
\hline Mass loss ratio/\% & 6.177 & 6.881 & 7.386 & 7.718 \\
\hline
\end{tabular}

\section{Conclusions}

(1) Microwave activation can effectively reduce the sulfur content of molybdenum calcine samples obtained from molybdenite. The reason is that microwave activation can improve the thermodynamic and kinetic conditions of the molybdenite oxidation roasting process and oxidize molybdenite more thoroughly than before treatment.

(2) After microwave activation, the specific surface area of molybdenite increased. The structural parameters and material properties of $\mathrm{MoS}_{2}$, the main component of molybdenite, were changed by microwave activation.

(3) With the extension of microwave activated power, the crystal cell volume and grain size of $\mathrm{MoS}_{2}$ reduced, the microstrain increased slightly, and morphologic features of the surface of molybdenite became looser.

(4) Microwave activation significantly changed the oxidation characteristics of molybdenite and promoted its oxidation reaction above $538{ }^{\circ} \mathrm{C}$. The weight loss rate increased from $6.177 \%$ to $7.718 \%$ at $620{ }^{\circ} \mathrm{C}$. The extension of activation time improved the conversion of molybdenite and accelerated the reaction rate of molybdenite. 
Author Contributions: Conceptualization, S.Y. and T.Z.; methodology, S.L. and H.S.; writingoriginal draft preparation, S.Y. and T.Z.; writing-review and editing, T.Z. and H.S; supervision, S.Y. and S.L.; All authors have read and agreed to the published version of the manuscript.

Funding: This research was funded by the "Project on new ferromolybdenum smelting thermodynamics and slag systematization (20200338)".

Institutional Review Board Statement: Not applicable.

Informed Consent Statement: Not applicable.

Data Availability Statement: The data presented in this study cannot be shared at this time as the data also forms part of an ongoing study.

Acknowledgments: The authors were appreciated for the precious comments and suggestions of the editors and reviewers.

Conflicts of Interest: The authors declare no conflict of interest. The funders had no role in the design of the study; in the collection, analyses, or interpretation of data; in the writing of the manuscript, or in the decision to publish the results.

\section{References}

1. Liu, Z.-X.; Yin, Z.-L.; Chen, Y.G.; Xiong, L.-Z. Leaching kinetics of molybdenum from Ni-Mo ore in sulfuric acid solution with sodium peroxodisulfate as oxidant. J. Cent. South Univ. 2015, 22, 874. (In Chinese) [CrossRef]

2. Lindstrom, R.E.; Scheiner, B.J. Extraetion of molybdenum from ores by electro-oxidation. Bur. Mines Met. Reeovery Progr. USBM Tech. Prog. Rep. 1972, 10, 4-7.

3. Hou, X.-C.; Yang, Y.-D.; Li, H.; Zeng, L.; Xiao, L.-S. Kinetics study of leaching arsenic from Ni-Mo ore roasting in dust mixture of hydrochloric and sulfuric acids. J. Cent. South Univ. 2014, 21, 2176. (In Chinese) [CrossRef]

4. Sharma, T. Physico-chemical processing of low grade manganese ore. Int. J. Miner. Process. 1992, 35, 191-203. [CrossRef]

5. Ren, B.-J. Production practice of molybdenum concentrate roasting by rotary kiln. Nonferrous Met. Extr. Met. 1999, 2, 18-20. (In Chinese)

6. Mehugh, L.F.; Barchers, D.E. Roasting of Molybdenite on Centrates Containing Flotation Oils. U.S. Patent 4,523,948, 18 June 1985.

7. Mehugh, L.F.; Godssehalk, J.; Kuzior, M. Climax conversionIII. In Proceedings of the Vancouver: The XVI Canadian Institute of Mining and Metallurgy Annu Meeting, Vancouver, DC, Canada, 8-10 August 1977.

8. Maheshc, J.; May, W.A. Fluidized-Bed Roasting of Molybdenites Concentrates. U.S. Patent 6,190,625, 20 February 2001.

9. Cao, Z.-F.; Zhong, H.; Liu, G.-Y. Electric oxidation kinetics of molybdenite concent rate in acidic NaCl solution. Can. J. Chem. Eng. 2009, 87, 93-94. (In Chinese)

10. Kim, B.-S.; Lee, H.-I.; Choi, Y.-Y.; Kim, S. Kinetics of the Oxidative Roasting of Low Grade Mongolian Molybdenite Concentrate. Mater. Trans. 2009, 50, 2669-2674. [CrossRef]

11. Abdel-Rehim, A.M. Thermal Analysis and X-ray Diffraction of Roasting of Egyptian Molybdenite. J. Therm. Anal. Calorim. 1999, 57, 415-431. [CrossRef]

12. Ebrahimi, K.; Reza, A.; Mohammad, H.; Saidi, A. Model-Fitting Approach to Kinetic Analysis of Non-Isothermal Oxidation of Molybdenite. Iran. J. Chem. Chem. Eng. 2007, 26, 119-123.

13. Gan, M.; Fan, X.-H.; Zhang, L.; Jiang, T.; Qiu, G.-Z.; Wang, Y.; Deng, Q.; Chen, X.-L. Reaction behavior of low grade molybdenum concentrates in oxidation roasting process. Chin. J. Nonferrous Met. 2014, 24, 3115-3122. (In Chinese)

14. Chen, X.-L.; Wang, H.-B.; Gan, M.; Fan, X.-H.; Zhang, L.; Deng, Q.; Wang, Y.; Zeng, J.-L. Extraction of molybdenum from low grade molybdenum concentrates by calciun-based roasting and acid leaching process. Chin. J. Nonferrous Met. 2015, 25, 2913-2920. (In Chinese)

15. Hu, H.-P.; Chen, Q.-Y.; Yin, Z.-L.; Gunter, G.; Zhang, P.-M.; Guo, G.-H. Structural Change of Mechanically Activated Molybdenite and the Effect of Mechanical Activation on Molybdenite. Met. Mater. Trans. B 2004, 12, 1203-1207. [CrossRef]

16. Yi, J.-H.; Tang, X.-W.; Luo, S.-D. Development and trend of microwave sintering technology. Powder Met. Technol. 2003, 21, 351-353. (In Chinese)

17. Yu, Q.; Ding, D.-X.; Zhang, J.; Hu, N.; Yang, Y.-S.; Wang, H. Application status and development trend of microwave irradiation technology in mining industry. Gold Sci. Technol. 2017, 25, 112-120. (In Chinese)

18. Kelly, R.M.; Rowson, N.A. Microwave reduction of oxidized ilmenite concentrates. Miner. Eng. 1995, 8, 1427-1438. [CrossRef]

19. Mourao, M.B.; Carvalho, I.P.; Takano, C. Carbothermic Reduction by Microwave Heating. ISIJ Int. 2001, 41, S27-S30. [CrossRef]

20. Farahat, M.; Elmahdy, A.M.; Hirajima, T. Influence of microwave radiation on the magnetic properties of molybdenite and arsenopyrite. Powder Technol. 2017, 315, 276-281. [CrossRef]

21. Guo, G.-Z.; Deng, G.-Y.; Tang, H.-Y. The characteristics of microwave drying process for molybdenum. J. Henan Univ. Sci. Technol. Nat. Sci. 2014, 35, 5-8. (In Chinese)

22. Jing, Q.-H. Chemistry of Microwave; Science Press: Beijing, China, 2001. (In Chinese) 
23. Kenkre, V.M.; Skal, A.L.; Weiser, M.W. Theory of microwave interactions in ceramic materials:the phenomenon of thermal runaway. Int. J. Refract. Met. Hard Mater. 2010, 28, 180-186.

24. Zhou, J.; Cheng, J.-P.; Fu, W.-B.; Dong, X.-B.; Mei, B.-C. Research on Improving Single Mode Cavity Type Microwave Sintering System with $2450 \mathrm{MHz} / 5 \mathrm{~kW}$. J. Wuhan Univ. Technol. 1999, 21, 2. (In Chinese)

25. Wang, M.; Yang, S.-P.; Guo, S.-Q.; Cao, S.-W.; He, K. Production of low-sulfur molybdenum oxide by microwave-activated pre-calcination of molybdenite. Rare Met. Mater. Eng. 2020, 49, 48-58. (In Chinese)

26. Alexiew, V.; Prins, R.; Webzer, T. Ab initio study of $\mathrm{MoS}_{2}$ and Li adsorbed on the face of $\mathrm{MoS}_{2}$. Phys. Chem. Chem. Phys. 2000, 2, 1815-1827. [CrossRef]

27. Luo, J.; Cai, C.; Lv, C.-X. Recent development of microwave-induced organic reaction chemistry. Chin. J. Synth. Chem. 2002, 10, 17-24. (In Chinese)

28. Zhou, X.-P.; Yan, L.-M. Investigation on microwave reaction mechanism of thiophene and its derivatives. J. Fuel Chem. Technol. 1998, 26, 506-509. (In Chinese)

29. Zhang, H.-L.; Hu, X.-M.; Lai, S.-L. The research into kinetic principle of microwave effect on chemical reaction. J. South China Univ. Technol. (Nat. Sci.) 1997, 25, 46-50. (In Chinese) 